\title{
University - society linkage projects: 20 years working with the underprivileged sectors in Ecuador
}

Jorge Altamirano Sanchez a *

Ignacio de los Rios Carmenado ${ }^{b}$

Suggested Citation:

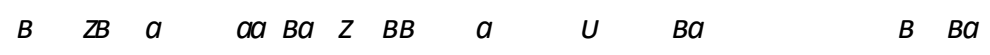

Abstract 
1. Introduction 
2. Methodology 


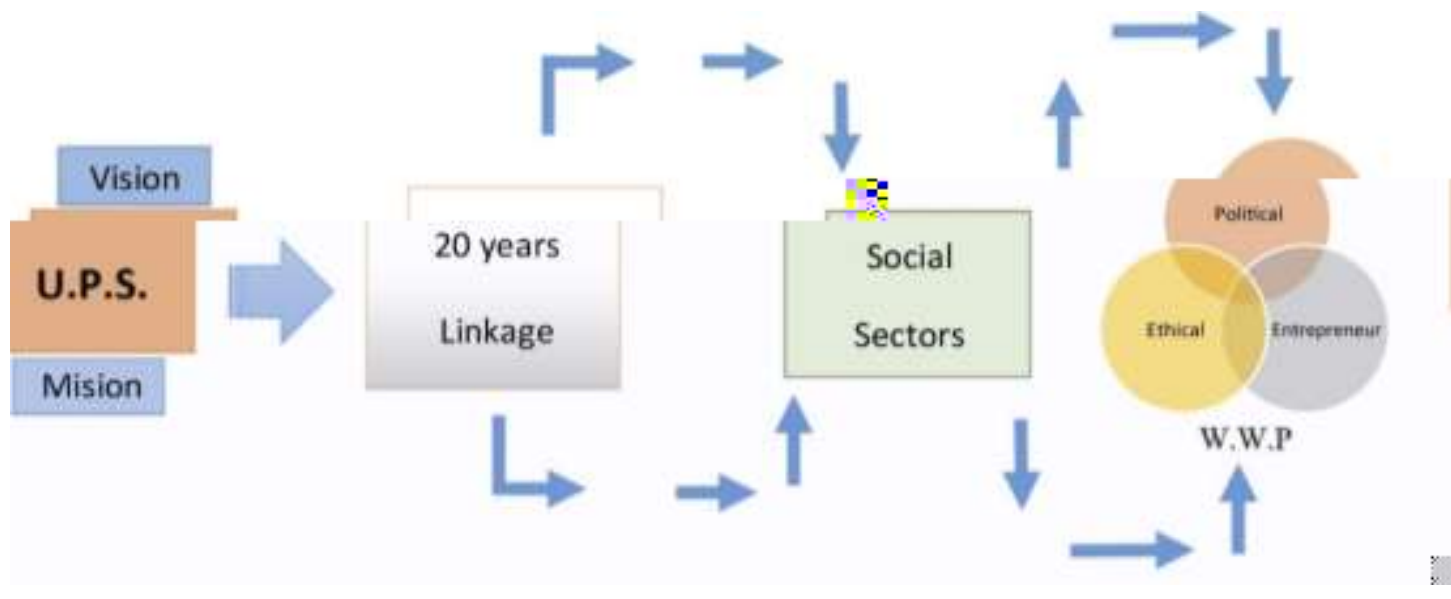

Figure 1.Research Methodology Scheme Source: Own elaboration (2016)

$B$

a B

$B$

$B \quad Z B \quad Z B \quad B \quad Z$

3. Obtained Results 
4. Conclusions 


\section{References}

$$
\begin{aligned}
& \begin{array}{lllllllll}
B & a & B & B & Z & & B & B a & B
\end{array} \\
& \begin{array}{llllllllllll}
B Z a & A B & Z & Z & Z B & B & a & Z B & B & B Z & B
\end{array} \\
& Z \quad Z \cup \quad a \quad B \\
& \text { B } \quad \text { a } \quad \text { a } \quad \text { B } \quad \text { a } \\
& \text { B } A \quad B \\
& u
\end{aligned}
$$

B $Z \quad B \quad B a$

$\begin{array}{lllll}B a & Z Z & \text { B } & \text { a } & B\end{array}$

$\begin{array}{lllllll}B Z & a & \text { в } & \text { Ba } & Z Z & Z\end{array}$

$B Z$

$$
z \quad B \quad z B B a \quad \cup \quad z \cup a B
$$

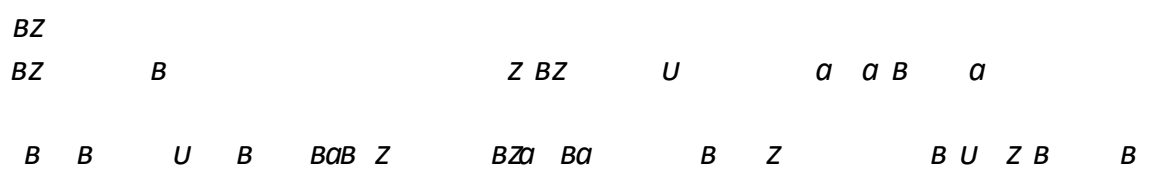
B Z
$B B \quad a$
$Z$
B
$\begin{array}{llll}B & a B & Z & Z\end{array}$
BZa B

B $\cup \quad a$

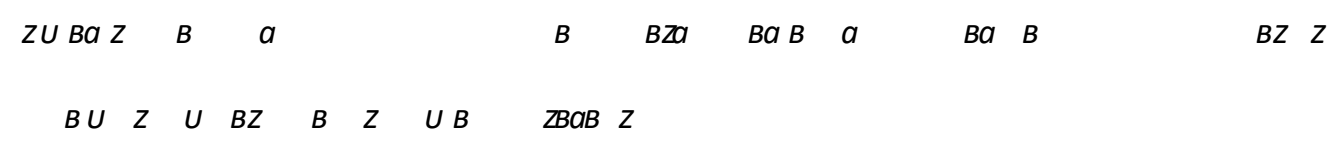

u $\quad a$
$B \quad Z \quad B$
$z \quad a B Z$

$B \cup B \quad B \quad B$

$\begin{array}{lll}Z & B & Z\end{array}$

$\begin{array}{lll} & B Z & \\ Z & a A B & B Z B\end{array}$


B $B a$

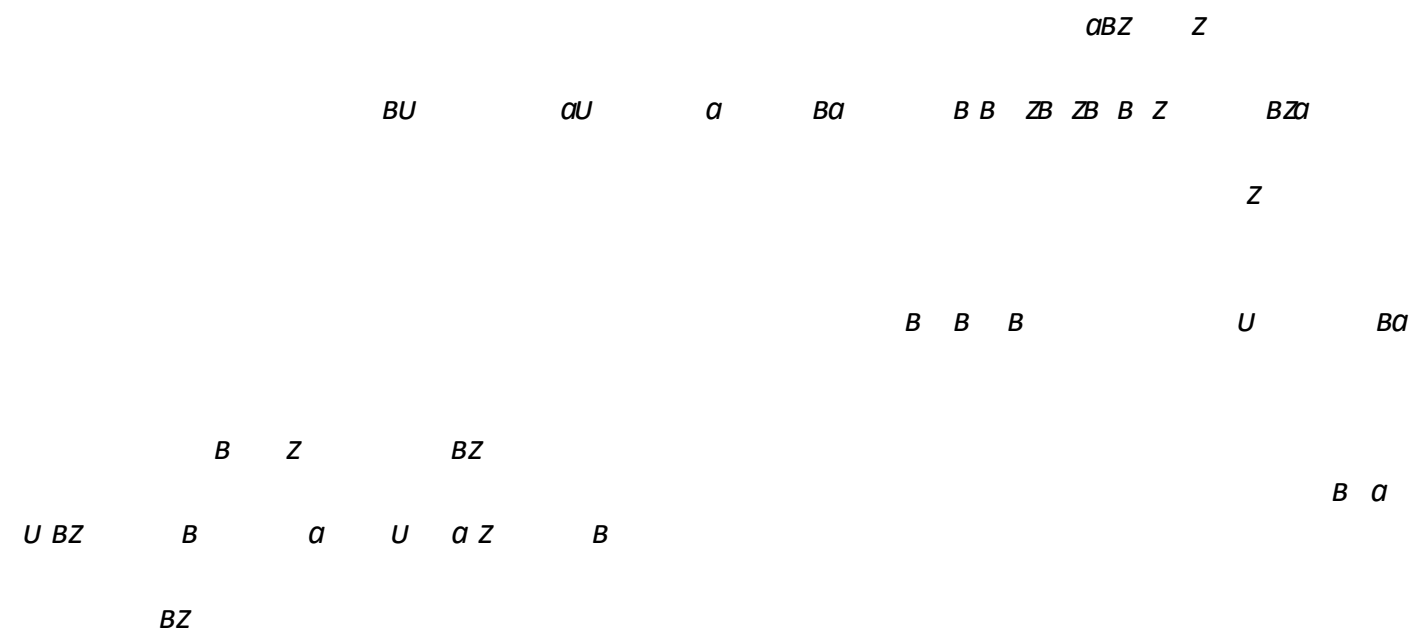

